\title{
A TYPOLOGY OF CREATIVE CITIES IN THE WORLD - LESSONS LEARNED
}

\author{
Berta Rato \\ Ana Roldão \\ Oliver Mühlhan
}

Dezembro 2009

WP no 2009/82

DOCUMENTO DE TRABALHO

WORKI NG PAPER

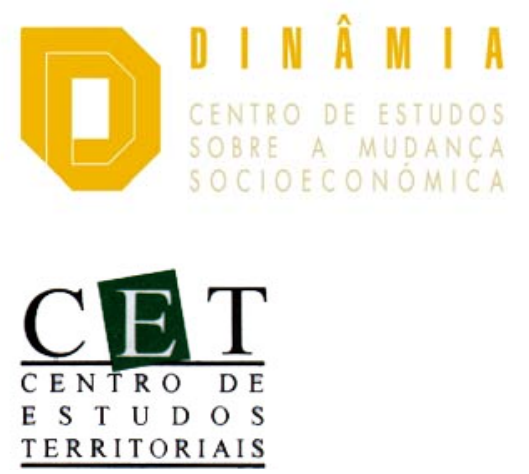

FCT 


\title{
A typology of creative cities in the world - lessons learned ${ }^{1}$
}

\author{
Berta Rato* \\ Ana Roldão**
}

Oliver Mühlhan****

WP n. 0 2009/82

Dezembro de 2009

2. CREATIVE INDUSTRIES, CREATIVE CITIES AND SOME EXAMPLES OF TYPOLOGIES

3. CREATIVE CITIES - A TYPOLOGY OF INTERVENTIONS

3.1 THE NATURAL BORN CITIES APPROACH

3.2 THE CULTURE-LED SOCIAL INCLUSION APPROACH

3.3 THE BUSINESS APPROACH

3.4 THE BULLDOZER-BUSINESS APPROACH

\footnotetext{
${ }^{1}$ This paper has been prepared within the framework of the research project CreatCity - "A governance culture for the creative city: urban vitality and international networks", conducted by Dinâmia (Research Centre on Socioeconomic Change of the ISCTE/Lisbon) and financed by Fundação para a Ciência e a Tecnologia/Ministério da Ciência, Tecnologia e Ensino Superior, with the support of ERDF and national funds of the MCTES (Refa. Proj. PTDC/AUR/65885/2006).

* DINÂMIA/ISCTE, Lisbon, Portugal and TAURUS ECO Consulting, Trier, Germany.

* DINÂMIA/ISCTE, Lisbon, Portugal.

** TAURUSpro, Trier, Germany.
} 


\section{INTRODUCTION}

In the last decades, the creative industries have been performing extremely well, in terms of job creation and growth of turnover, in comparison to other sectors. Creative industries are located mainly in cities or agglomerations, as they need, more than other economic branches, a high density of people, companies, contacts and exchanges. In addition, they provide good chances to stabilize quarters in decline, to start renewal interventions, to support economic growth or to promote social inclusion.

So it is not a surprise that creative industries and the fostering of creative cities have become part of the political agendas and of local and regional plans of action all over the world. Strategies are translated into a policy mix of interventions combining the economic, social and urban development dimensions.

The number of interventions to promote "creative cities" is even now increasing. The actors in charge of local and city development keep drafting and carrying out measures to stimulate or to strengthen their creative industries, with more or less success.

There are several publications and research documents which testimony successful cases of creative cities. Some of them focus as well on the difficulties that these cities have faced in the implementation process and on recommendations for a successful intervention. Two researches are particularly motivating, the first is the study on "Strategies for creative spaces" from the London Development Agency (LDA, 2005, 2006), which concludes on how to improve the delivery of creative economy strategies, in general, and how to maximise the role of the creative economy in the competitiveness of London and Toronto, in particular; the second, is Landry's (2000) "mental toolkit" to support decision-makers in their solutions for their cities.

What seems to be absent from the literature is, on one side, a more broad understanding of policies for the nurturing of creative cities, embracing at the same time the social, urban and economic dimensions, and, on the other side, establishing a correspondence between a specific type of approach and the corresponding challenges, risks and recommendations.

It is the objective of this paper to bring local policy-makers support for the spotting of their strategies in the panorama of creative cities policies, but furthermore to provide some warnings about what is at stake when implementing one or another type of policy, what are the challenges, the risks and lessons learned from other cases.

We propose as a tool a typology of different types of approaches aiming at the development of creative industries and their specific challenges, characteristics which can lead to failure and recommendations. In this way, policy-makers can easily identify their strategy with a particular approach and to look in detail at the key-questions resulting from the 
experience of other cities. The definition of our typology is the result of the analysis of several case studies (not extensively mentioned in the paper), based on desk-top research and on interviews for the our research project ${ }^{2}$.

In the first section, we will go through the academic debate on creativity, concepts and typologies. In the second section, we will explain our tool - the typology of interventions, the dimensions considered and the specific attributes of the different categories. The third section, discusses in detail the seven sub-groups, explaining for each their common background, objectives and measures, but also their recurrent challenges, threats and prevention measures to be considered. Finally, the paper draws together some overall lessons to be taken into consideration by decision-makers.

\section{CREATIVE INDUSTRIES, CREATIVE CITIES AND SOME EXAMPLES OF TYPOLOGIES}

The recognition of the importance and the continuous expansion of the cultural and creative industries has lead to significant interest of researchers and policy-makers, which have been discussing and analysing the concepts of "cultural industries" (Adorno and Horkheimer, Towse), "creative industries" (Caves, DCMS), "creative cities" (Landry, Hall, Ralph Ebert), "creative class" (Florida), "creative Europe" (ERICArts), “cultural economy” (Scott).

It is not the focus of this paper to discuss extensively the different concepts and their evolution, nevertheless considering that our typology covers different nations with distinct definitions of creative industries, it is recommendable to examine some concepts and classifications.

Towse (2000, p.170) proposes a very operational definition of cultural industries: "Cultural industries mass-produce goods and services with sufficient artistic content to be considered creative and culturally significant. The essential features are industrial-scale production combined with cultural content”.

In the 1990s the term "cultural industries" proved to be insufficient considering the policy context, as Hartley argues (2005, p.14), "it failed to combine art and culture, culture and creativity. It failed to take advantage of social, technological, and cultural changes (...)". The new concept of "creative industries" which emerged at that time revealed to be much more flexible and wide-ranging, representing according to Hartley (p.18) "the commercial, or commercializable, applications of creativity within a democratizing "republic of taste"'".

\footnotetext{
${ }^{2}$ Please see note 1.
} 
The fuzziness of the conceptual background is transmitted to the mapping and definition of the creative economic branches. These vary from country to country, reflecting historical developments and the consequent national or regional characteristics of the creative or cultural industries sub-sectors. As Hartley points (2005, p.5), "in the USA creativity is consumer- and market-driven, whereas in Europe it is caught up in traditions of national culture and cultural citizenship".

The UK Creative Industries Task Force in 1997 (DCMS, 2001) proposes one definition which is broadly used: "industries that have their origin in individual creativity, skill and talent and which have a potential for wealth and job creation through the generation and exploitation of intellectual property". The Department for Culture Media and Sports (DCMS) considers 13 activities within the creative industries sector: advertising; architecture; the arts and antiques market; crafts; design; designer fashion; film and video; interactive leisure software, music, performing arts, publishing, software and computer services; and television and radio. Another British institution, the National Endowment for Science, Technology and the Arts (NESTA), proposes a more comprehensive approach, which includes four groups of creative activities: “service providers”, “content producers”, “experience providers” and “originals producers”. This model highlights the contribution of creative industries to economic and local development and in particular the role of tourism and heritage, considered to be situated in one overlapping area between the "services providers§ and the "experience providers". (NESTA, 2006)

In countries influenced both by Europe and by the USA, e.g., Singapore, New Zealand or other Commonwealth countries the creative industries reflect both poles - consumer and culture, market and citizenship. As a consequence, in Australia IT and software services has also been added to the traditional classifications and the "Singapore Model" is even broader embracing as well all the distribution services (e.g., bookshops, video shops, film projection).

As a consequence, international comparisons of creative industries policies have to bear in mind that the concepts behind and the resulting statistical definitions are not harmonised, demanding some caution.

The creative industries have their natural place in agglomerations, specially in bigger agglomerations, which allow the gathering of some essential economic and non-economic conditions, such as diverse agglomeration economies, facilitating the consolidation of cultural clusters, openness to innovation and to difference, high density of actors of Florida's "creative class" (enhancing the access to networks and informal contacts) or a multi-cultural cosmopolitan environment. (Costa, 2008)

There is a broad sample of definitions of creative cities, some more policy-making oriented, others more academic. Costa (2008), in a very noteworthy attempt of synthesis, suggests a typology to explain the creative city notion, based on three known approaches: (i) the 
creative cities and creativity as a toolkit for urban development (developed by Landry, 2000); (ii) the creative city as a city with a strong dynamism of the creative productive sector (concept explored by Pratt, 2004 and the DCMS); (iii) the creative city as a place with the capacity to attract creative competences, that is, creative human resources (Florida, 2002).

The interest of being or becoming a "creative city", with sound creative industries, is in principle obvious - creative industries are one of the most dynamic economic sectors, generating added value and new jobs ${ }^{3}$, and, in parallel, promoting chief location factors such as urban vitality and a first-class image relevant also for companies from other sectors.

Policy-makers and politicians of creative cities or "wished to be" creative cities have invested appreciably in the last two decades in all types of measures, of physical and immaterial character, to cherish their creative industries.

The diversity of these initiatives has been the focus of several authors and studies. Sir Peter Hall in a presentation in Berlin ${ }^{4}$ brings into discussion a typology comprised of three groups of cities: 1) Old-Established Metropolitan Cities, such as London, Paris or New York, which have all the resources to be successful, for instance prestige cultural equipments, universities, qualified population, financial capacity; 2) Favoured Sunbelt Cities, like San Francisco, Vancouver or Sydney, which combine several advantages - good natural resources, climate, urban ambience and a favourable cultural and educational milieu, 3) Renaissance Cities, for instance Glasgow, Bilbao, Manchester or Newcastle-Gateshead, with a common past as old industrial or port cities and similar responses creative-led to the challenges of deindustrialisation.

This categorisation is based on the historical and cultural factors which allowed these cities to assume a certain position in the global markets. This approach offers the advantage to consider the territory of a city as a homogeneous creative space and to enable some cities to identify themselves with a certain type. Conversely, the categories are too broad and a few cities may be left out.

The study "Strategies for creative space and cities project” (LDA, 2005), a collaboration between researchers from London and Toronto, proposes an organisation of types of intervention focused on space and type of intervention. Based on a preliminary analysis of policies from around the world, six types of strategy are put forward (LDA, 2005, pp.15-18): 1) Property and premises - dedicated workspace to creative activities, e.g., science parks, live/work facilities, showcase spaces, design centres; 2) Business development, advice and network

\footnotetext{
${ }^{3}$ In Europe, the economy of culture amounted to 2.6 per cent of the GDP and a turnover of 654 billion EUR, in 2003. Further, these activities are important creators of employment: between 2002 and 2004, the number of jobs has grown by 1.85 per cent, while in Europe the overall number of jobs was decreasing. (KEA, 2006)

${ }^{4}$ Hall, Peter (2007).
} 
building - specialised services for the creative/cultural industries (e.g., marketing, financing, training); 3) Direct grants/loans to creative business/entrepreneurs; 4) Fiscal initiatives - direct and indirect taxation and incentive schemes; 5) Physical infrastructure - quality of environment, buildings, facilities and public realm/spaces; 6) Soft infrastructure - education, training and measures to change mentality.

This very comprehensive typology is a good overview of the multitude of spatial interventions, however by focusing on space and on the means or concrete policy-instrument applied, overlooks to a certain extent the initial aims and motivations of the strategies to promote the creative industries - just economic development or other complementary objectives?

\section{CREATIVE CITIES - A TYPOLOGY OF INTERVENTIONS}

Our typology of interventions presents a different focus; it crosses over the motivations which triggered the creative-led strategy with the methods which were applied for its implementation. In addition, it is flexible enough to allow the consideration of different areas and strategies within the same city.

Evidence shows that interventions have three main purposes: 1) economic development, 2) social inclusion and 3) (physical) urban development. The economic development dimension is the core aim of creative cities interventions. All policy-makers wish to encourage the creative branches in order to promote new jobs, new activities and to improve the image of the city or the region. The social inclusion dimension is mainly present in programmes with a strong social character and a community-focus. The urban development dimension represents the interventions with a physical component, for instance renovation of large city areas, construction of prestige buildings and requalification of city quarters.

Creativity strategies possess such a multifaceted nature that there are very few interventions which are really pure, consisting of actions strictly economic, physical or social. Most of the interventions are a combination of different kinds of actions, pending more to one or another dimension. However, the identified dimensions are not enough to properly describe the particularities of creative cities interventions and to identify their corresponding challenges. Other attributes are determinant: 1 ) the creative historical assets of a place (a past related to creativity or not); 2) the territory of the intervention: quarter(s), city, region; 3) the main beneficiaries from the intervention: the State, the region, the city, the community, a particular group of actors, the private sector; 4) the level of participation of the population in the process:

top-down or bottom-up; 5) the extent of the physical intervention: heavy intervention 
(renovation, construction of an emblematic building, transport networks,...) vs. renewal of buildings and requalification of quarters (qualification of public space, community public art).

The figure bellow pictures our proposal of typology of creative cities. The three keydimensions - social inclusion, economic and urban development are the starting point. Then considering the secondary attributes it is possible to categorise the cities according to seven different approaches.

a) The Natural Born City approach, with a similar focus to Hall's "Old established metropolitan areas”, is marked by its holistic nature: a myriad of interventions in all fronts. We are in the presence of normally large cities, often capital cities, possessing numerous assets of all kinds, e.g., Toronto or London.

b) The Culture-led Social Inclusion approach clearly reflects the social dimension. Though many projects may be supported by the qualification of space and by the promotion of some economic activity, these objectives are normally just complementary. The German programme Socially Integrated City provides illustrative examples.

c) The Business approach is very close to the economic domain. The actions to be undertaken should contribute to the expansion of the creative industries. Physical investments are not so relevant. Singapore (promotion of two specific clusters - design and media) and Vienna (promotion of a creative cluster) represent this approach.

d) The Bulldozer-Business approach is situated near the physical/urban development dimension. It describes interventions with a strong physical impact. The impulse to undertake these actions comes mainly from the public sphere, but the interventions are normally carried out within a Public Private Partnership. Good examples of this approach are Barcelona or the Salford Quay urban development in Manchester.

e) The European Capital of Culture (ECC) approach describes the particularities and the challenges of these policies. The aim of the first ECC interventions was mainly cultural, but more and more the orientation is towards the economic development of the city or of a particular quarter.

f) The Enhancing approach is influenced by the three dimensions. This category combines the improvement of space, with the renewal of buildings or quarters, but without large scale interventions. The "cultural quarters", such as the Cultural Industries Quarter in Sheffield, portray well this approach.

g) The Phoenix approach represents all interventions which, starting from a close to zero creative industry, that is a meagre economic tissue of creative industries and a low tradition of consumption of cultural goods, have succeeded in inverting this situation, e.g., The Ruhr area in Germany. 


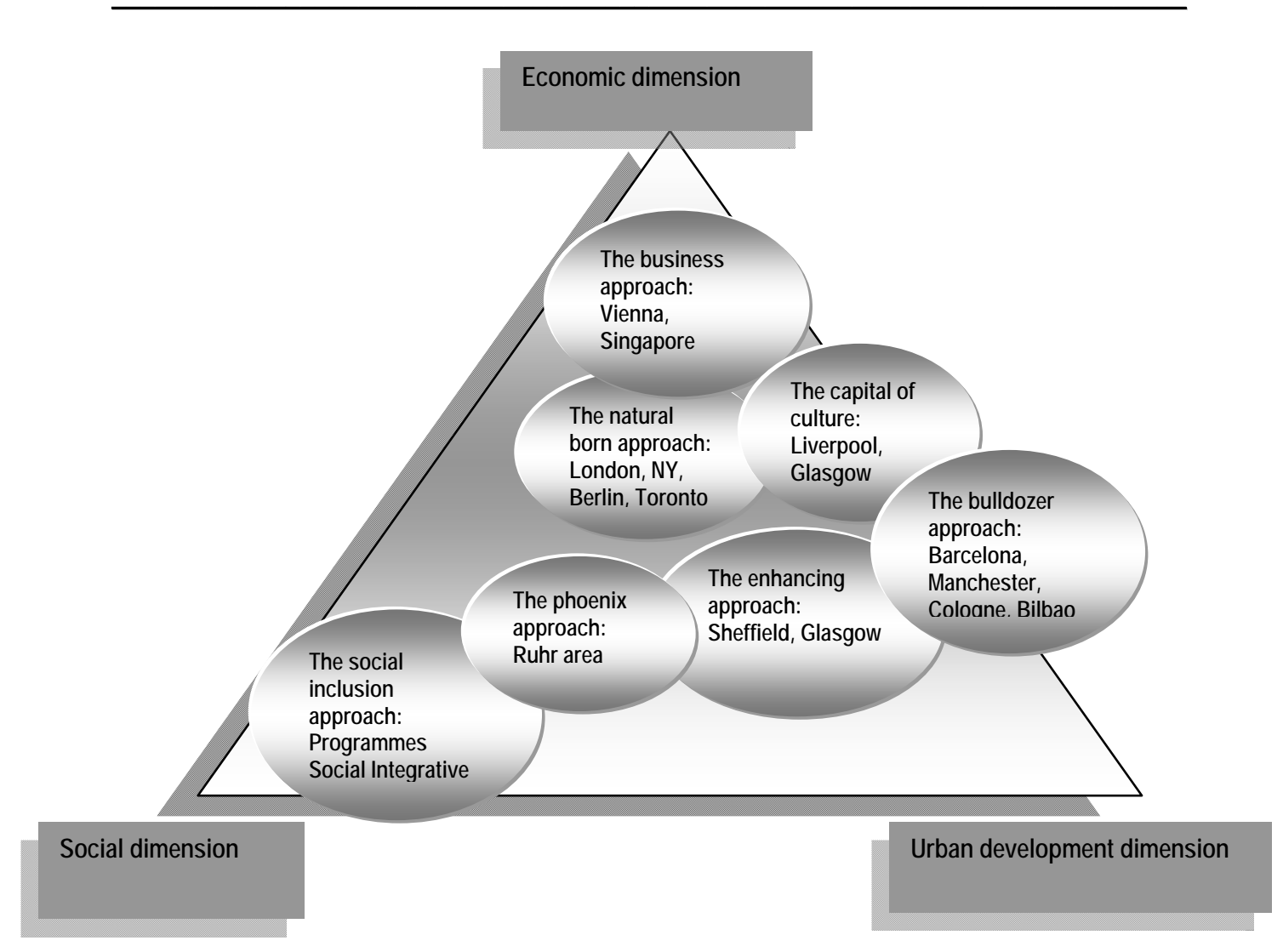

\subsection{The Natural Born Cities approach}

We can call "natural born cities" those cases where, by existing a past of cultural and creative industries, key equipments with a national area of influence and more financial possibilities, creative industries have developed on their own, pushed mainly by the private sphere. Usually, those are the largest or the capital cities, with a "diversified, sophisticated and internationally oriented cultural industries structure that nurtures and supports a wealth of local and international artistic activity commercial, subsidised and voluntary “(Landry, 2005, p.235).

Nowadays, recognising the potential of these cities and trying to anticipate potential threats, policy makers are taking account of these issues on the local agendas, base for a multitude of creative and cultural led-policies: renovation of derelict areas and enhancement of creative clusters, construction of symbolic cultural equipments, promotion of flagship events, culture-led social inclusion interventions or economic incentives. London, Berlin and Toronto are some examples that can be included in this typology.

London, as a capital city, has a high concentration and critical mass of production, distribution and consumption, activity and employment. In 2005, 7 to 9.2 per cent of the GDP are related to the creative industries. However, the Mayor's Commission on the Creative Industries recognised that, although many of the earlier programmes have had success, there 
was a need for a more extensive and longer-term approach to expand creative industries. So, in 2004 a Cultural Strategy to make London a world-class creative city was presented. The strategy was characterized by the support to local 'creative hubs', investment on sectors such as film industry or design, plus a range of cross-sectoral initiatives that were expected to bring potential benefits to creative enterprises. The aims were manifold: to help local leaders to create a new vision for their inner city by identifying market-based strategies and engaging the private sector; to make the inner-city more competitive; to increase income, wealth and job opportunities for local residents; to create leadership and institutions that would push the agenda forward.

The Creative Industries sector is also an important part of Berlin's labour market (in 2002, Berlin's creative economy was estimated to account for 3.6 per cent of Germany's GDP and 8 per cent of the employment). The city possesses important strengths that contribute to this success, for instance: interesting location; high density of clients/firms and public educational facilities; good reputation, a 'creative milieu', cheap space for working, good concentration of independent freelancers.

In Toronto, in 2001, 6 per cent of the employment of the whole metropolitan region was in the creative sector. The City Council has developed a plan of Culture to help guiding and placing Toronto in the international sphere and to define culture as an engine of economic and social development. The city primary focus was on the non-profit sector and its capacity to serve the broader community. Further the city invested on large capital projects to expand the city arts and culture district, always relating this process to the fostering of the tourism sector.

Despite all the optimism, all these cases face difficulties and challenges. The most severe uncertainties come from the economic sphere. First, the raise of real estate costs, due to gentrification and the requalification of the areas, conditions the attraction and the maintenance of artists and other creative talents. This problem happened in, for instance, in the Hoxton Square in London where the live/work quotas for creative people were decreasing dramatically. Second, the insufficiency of public budget may compromise the long-term sustainability of the strategy: in Berlin, this is at present a serious problem - paraphrasing the Mayor: the city is "poor but sexy". In Toronto, accumulated deficits and a severe shortage of working capital have also grave consequences for the strategy development. Third, these cities are extremely exposed to international competition. In addition, the creative class reveals structural limitations, on the field of entrepreneurship and marketing skills, which condition their competitiveness.

Another limitation of cultural programmes or strategies is the incapacity to address all the population segments including minorities and to have a proportionate employment of these groups within the creative sector, which could contribute to attenuating social and ethnic problems. In London, although there have been cultural initiatives associated to social inclusion 
agendas (e.g., the increase of role of minority groups in the creative industries professional basis), the results were unsatisfactory.

A particular challenge for the Natural Born cities is the governance of the creative strategy. In many metropolitan areas or capital cities (and in all our three cases), evidence shows the lack of an overall creativity-led strategy, translated in the absence of connections between sectors, policies, plans, programmes. In Berlin, for instance, an integrative strategy which relates the cultural/ creative sector with the strategic policy framework for the city as a whole city plan is missing. In Toronto, all planning levels - local, regional, national and in addition the cultural sector, implement their own cultural and creative strategies, without an overall coordination, this leads to the overlapping of funds for some areas and policy and financial gaps in others.

Although "natural born cities" have all the conditions for some kind of self-governance, in the long term this may not result. It will be necessary some support for this creative city status to become more "embedded and mature" (LDA, 2006b, p.14). Furthermore, the future of creative industries has to be sustained on networks that integrate industries sectors to all the planning processes and by understanding governance modes that approaches private, administrative agents and civil society in general (Lange, 2008, p.539).

\subsection{The Culture-led Social Inclusion approach}

The approach social inclusion embraces interventions which address mainly social objectives. They are characterised by: i) the location in a specific territory, normally a city neighbourhood, with recognised social difficulties, ii) the orientation to support the local residents; iii) the integration of the neighbourhood in the rest of the city. The interventions combine in many cases light physical intervention, such as housing renewal, improvement of public spaces, with soft cultural policy measures such as the installation of cultural facilities or the support and promotion of cultural activities in a wide sense. Some interventions go further and explore the relation between cultural activities and economic development. Public institutions, non-profit organisations and the community play an important role.

The policies considered within this approach are based on the acknowledgment that " arts, sports, cultural and recreational activity can contribute to neighbourhood renewal and make a real difference to health, crime, employment and education in deprived communities" (Brookes, F., 2004). "Art and cultural projects can help integrate sections of the population which are otherwise hard to activate. Planning and running projects of this kind do not demand special language skills or intellectual ability. Instead it requires imaginative and creative people open to new ideas" (Soziale Stadt, 2002, p.2). 
Several studies on the social impacts of promoting cultural policies in deprived quarters (Brookes, F., 2004, Matarasso and Moriarty, referred to in Evans, G. and P. Shaw, 2004) are unanimous in recognising that cultural activities can contribute: 1) at a personal level, to an increased confidence and self-esteem, health and well-being, new qualifications, democracy and citizenship, therefore facilitating employment and integration; 2) at the community level, to the preservation of culture, specially in the case of communities with a strong share of immigrants, to social cohesion, by means of strengthening the community identity and empowerment or by facilitating the communication between the residents; 3) in more ambitious interventions, to economic development, e.g., by the provision of local services or the support to the creation of businesses.

More and more cities are aware of this potential and try to implement social inclusion strategies based on culture. In the EU, several programmes dealing with the regeneration of urban areas, based on community-led initiatives, such as the European URBAN programmes or national social programmes, have provided a vast array of interesting experiences.

The German programme "Soziale Stadt" (Socially Integrated City Programme) is one of the most remarkable cases. The Programme, which started in 1999, envisaged to counteract the widening socio-spatial rifts in the cities, fostering participation and cooperation, and represented a new integrative political approach to urban district development. The acknowledgment of the relevance of culture for the attainment of the overall goals is the identification of "urban district culture" as one of the "substantive activity areas". ${ }^{5}$

Though in 2000, only 4 out of 100 of the "Soziale Stadt” projects contemplated cultural activities, nowadays 72 per cent of the 187 intervention areas envisage cultural objectives and 24 per cent consider the later as very important. The interventions within this programme are diversified, in terms of objectives and activities. There are four types of initiatives: 1) the plain "cultural projects", which aim at the development of creative potential and forming and strengthening identity. They are closely related to image upgrading, participation, adaptation and improved communication” (Sozialstadt, 2002, p.2), e.g., organisation of local festivals, theatre productions or musical performances; 2) the "projects to build and strengthen identity", particularly relevant in districts with high rotation of residents, e.g., the location of art and cultural centres; 3) the "image enhancement projects" present different approaches, one interesting case is the collaboration between neighbourhood children and artists for street painting schemes or graffiti projects; 4) the "communication and empowerment projects" include for instance the cooperation between universities and colleges with art and cultural

\footnotetext{
${ }^{5}$ Quotation from the Programme website: www.sozialestadt.de.
} 
studies departments or local associations with the neighbourhoods, providing premises for events.

In the United Kingdom, many cities also address social exclusion by means of culture and creativity. In Birmingham, the focus is to engage and nurture the talent of creative individuals considered as disenfranchised, in particular of BME (Black Minority Ethnic), to increase their employability ${ }^{6}$.

The main challenge of culture-led social inclusion initiatives seems to be the sustainability of the interventions. The need to create conditions which will allow the dynamics generated to have long lasting effects.

The experience provided by the regeneration programmes dealing with the target-areas communities (e.g., URBAN and the Socially Integrated City Programmes) is a worthy source of lessons to tackle these challenges. The Socially Integrated City Programme recommends to: 1) make clear from the beginning and discuss extensively with the community that the supporting measures and financing will have an end; 2) promote cooperation and local network structures and involve them in the decision and implementation processes, in order to motivate the community to participate and to become more independent - depending on the cases, external support, by means of moderation and coordination may be necessary; 3) support the capacity of the residents to organise themselves, in associations and initiatives; 4) keep a decentralised coordination and management structure, responsible for the animation and participation of the residents in further activities; 5) promote the involvement of the private sector ${ }^{7}$.

\subsection{The Business approach}

The objectives of the Business approach are the strengthening of local companies, attraction of new ones belonging to the cluster and in general the growth of employment and of income. The measures can as well be diverse, but clearly dominated by an immaterial nature. The main beneficiary is the private sector. The State or the Regions are the engines of this approach, the private sector is often an important partner.

In most cases the strategy is influenced by the concept of cluster, even if not explicitly admitted: the objective are the fostering of the concentration of companies of complementary branches in a building or one particular area (e.g., media cities), the encouragement of the establishment of networks between the actors, the provision of tailor-made services (R\&D, education, training, ...) and the development of synergies between the companies/actors.

\footnotetext{
${ }^{6}$ Carey, Charlotte (2006).

${ }^{7}$ www.sozialestadt.de.
} 
The strategies under the Business Approach consider in many cases a broader definition of creative industries, including IT and software development. Some strategies may have a more wide-ranging scope and others a more focused approach, with the support to only one or two key-sectors.

Vienna and Singapore are two representative examples of this approach, both advocating that their strategy is oriented to build a successful creative cluster, nevertheless the strategies of the two cities are different. Vienna relies much more on national capacities and is predominantly oriented to the national actors ${ }^{8}$. Singapore, due to the limited local market size and the lack of critical mass in some domains (e.g., education), is much more turned to the outside, as depicted by the important incentives for the attraction of talents and the export orientation of the companies ${ }^{9}$.

The tools for the implementation of the Business Approach are particularly imaginative, comprising actions to increase talents, ensuring an adequate regulatory framework, finance the implementation of creative projects, provide adequate spaces for the installation of creative activities and above all the foundation of a coordinating institution (or a set of institutions) responsible for the carrying out and for the general coordination of all the measures.

It is not so easy to conclude on the overall results of the Business Approach experiences. First, because in some cases the initiatives are very recent, therefore it is still too early to identify results. Second, in many cases, the policies aim at the consolidation of already settled creative industries or even clusters, so it is not feasible to distinguish the effects of these policies from the current economy trends, without complex economic modelling. Finally, the politicians and the policy-makers want to provide evidence on the great success of their policies (and the significant investments), therefore the existing studies are in general very optimistic. Nevertheless, considering that in the known cases of cities or regions which followed a Business Approach the creative sectors are progressing well, creating new jobs, income and helping to make the cities attractive, we can at least conclude that the impacts are not negative.

For bigger cities with higher ambitions, such as Singapore, London, Berlin, the intensification of international competition regarding the attraction of creative industries and creative talent may jeopardise or minimise the effects of the political agenda or increase immensely the costs for its accomplishment.

The policies to promote clusters imply additional challenges. On one side, challenges due to the particularities of the creative industries and the distinct types of actors involved. Policy-makers should avoid to include "in the same basket" the more artistic-led and the more business-led actors. On the other side, challenges arising from some typical features of any

\footnotetext{
${ }^{8}$ Kulturdokumentation, Mediakult, Wifo (2004).

${ }^{9}$ ERC Services Committee (2002).
} 
cluster to become successful: the existence of a minimum of critical mass (e.g., human resources, an economic base, communication between the actors or the will to interact) and a unambiguous definition from the starting of the cluster policy of aspects such as the targetgroups, the services to be provided and the expected complementary investments (e.g., on education and training).

\subsection{The Bulldozer-Business approach}

This approach describes interventions with a strong physical impact, where a whole quarter, normally a derelict abandoned area, is the target of a significant urban intervention which completely changes its face. In all cases, large, often close to downtown areas, have been completely or almost "cleared", that is freed of all existing constructions and covered with new buildings and surroundings (e.g., Barcelona 22 ha, Bilbao 16 ha, Köln 20 ha, Manchester 80 ha). A precondition for this approach is the availability of a sufficiently large contiguous area (ideally old industrial areas, ports or freight stations), more or less free from residential buildings and economic activity, which allow to set up something radical and completely new, without much public resistance. These areas should be ideally, but not necessarily, near to the city centre.

These interventions are focussed on new buildings, often with a spectacular, eyecatching architecture and new environments like squares, parks, boulevards or river fronts. An important facet is that the restructuring measures are carried out, with such an intensity, that the works are concluded in a relatively short time. The approach aims at creating something new and powerful which should act as a notable "bang" with effects spreading all over the city.

Due to the profit orientation of the heavy investments, the new buildings are in most cases home to representative offices for advanced creative industries, devoted to the media, IT or design/advertising/marketing, or flagship cultural institutions, mostly museums, institutions of higher education, halls for events, cinema complexes. In some cases a part of the office spaces are designated as incubators for start-ups or spin-offs, aiming at the development of creative activities clusters (e.g., media cities).

The economic impact of the intervention is always seen for the entire city, not only for the district. Good examples for the Bulldozer-Business Approach are the Media Park/District 22@bcn, in Barcelona, the Salford Quay urban development, in Manchester, the Abandoibarra quarter, area of the Guggenheim Museum, in Bilbao, or the MediaPark, in Cologne.

The initiative for these large projects comes usually from the local authorities, which should have the will to invest substantial public funds. Increasingly, and following some severe bad experiences of local communities, with dramatic consequences for the community finance 
(e.g., Sheffield and Birmingham), other stakeholders are more and more involved (e.g., national funding, participation of the private sector - public-private partnerships), for instance in Salford Quay Media City, in Manchester (Loftman and Nevin, 1996).

The integration or linkage to the existing city is also of great importance, because a "critical mass" of visitors is to be attracted by the site - a construction in open countryside /greenfield seems less promising.

A particularity of this approach is a certain disregard on the existing urban structures, both in structural or physical terms and social terms. In general, the local residents have had little or no participation at all in the decision and detailed planning. Quite on the contrary, the new urban complexes are consciously planned as a counterpoint to the existing city or to the surrounding neighbourhoods. This has provoked in many cases (e.g., Bilbao, Barcelona, Manchester or more recently in Hamburg) more or less strong reactions from the local population or from the creative class of the nearby areas or even of the intervention area. An illustrative case is Barcelona. The initial planned intervention, oriented to promote four hightech clusters, ignored completely the dynamics of the space, and the "rights" of the local creative scene hosted in a couple of historical factories to be demolished. It was a top-down intervention that have not helped nor promoted the process of creativity and social diversity: it was based on an artificial logic of creation of mixed uses, without a real integration between the city and town planning practice. However, the population from the nearby neighbourhoods and the creative people organised themselves and faced the promoters of the intervention, which ended up revising the initial plan in order to adopt at least part of the proposals of the local artistic community (Marti, s/d, Oliva, 2003).

\subsection{European Capital of Culture Event approach}

The first European Capital of Culture (ECC) took place in Athens in 1985. The initial events were very much oriented to intercultural objectives, such as: "helping to bring the people of the member-states closer together" (European Commission, 1985) and "making the culture of the cities accessible to a European Audience, and at the same time to create a picture of European Culture as a whole” (Corijn and Van Praet, 1994, referred in Richards and Wilson, 2004, p. 1936).

Nowadays, there is a different vision. Besides the cultural development and integration, new features, intentions and proposals are considered, such as revitalizing urban quarters, developing an economic tool by generating profits, increasing tourism or improving the international image (Richards and Wilson, 2004). More recently, a new dimension has been integrated, for instance in Liverpool and in Luxembourg, special attention was given to the 
participation of the local residents, not only as spectators, but also in the implementation of the events.

Each single ECC event that took place in Europe throughout these 22 years had specific orientations, methods and means. Glasgow (1990) and Luxembourg (2007) are two interesting examples of different backgrounds and approaches.

Glasgow, during the 80's, represented one of the most extreme cases of a post-industrial city, embodied in high economic problems and a rapid demographic decline. The City of Culture title was used to restore its image into an attractive and culturally interesting contemporary city and service-driven oriented, by putting emphasis on arts and cultural sector and acting as a tool to drive economic and urban regeneration (Reason, 2006, p.75). Therefore, there was an ambitious urban redesign programme, centralized in an important infrastructural implementation and in a commercial sponsorship.

Luxembourg is the only city which has held this event twice (1995 and 2007). In the edition of 2007, the territory considered was the whole Greater Region (Lorraine - France, Wallonia - Belgium, Rhineland-Palatinate and Sarre - Germany) in an effort to promote crossborder cultural cooperation. The target of the initiative was to stimulate cultural activities. The intension was to achieve durable cultural connections among all the actors involved, to mobilize different target-groups and to put emphasis on the contemporary and locally-based creativity rather than international blockbusters. The 3.3 million visitors were the expression of its success, both in economic terms (the overall economic balance was fairly positive) and in the cultural sphere (new audiences were reached and new participants and creators into the cultural scene appeared). Moreover, it is argued that the exhibition was a great success in terms of social cohesion (working with a mix of different social groups, from the different regions) and that the long-term impacts were positive: the new cultural spaces created will go on having their cultural function and the collaboration between the regions and the actors seems also to be long lasting ${ }^{10}$. Nevertheless, like in most (or all) ECC there is a general feeling from the local cultural-actors of a drastic fall in cultural animation and financial support in the following years.

The implementation of a European Capital of Culture, though in general achieving major and more visible aims, is not exempt of risks and of unexpected negative impacts. The evidence from previous editions has shown that important aspects such as social inclusion, economic sustainability or cultural developments have in some cases been relegated to a second plan

Some authors point out the too global reality approach, which through serial reproduction or serial monotony can result as merely cosmetic products, too far from the real

\footnotetext{
${ }^{10}$ Richards, Greg et al. (2008).
} 
identity of a city (Reason, 2006, p.78; Richards and Wilson, 2004, p.1932). In addition, one of the most referred dangers is the creation of an accidental and subservient cultural product (Reason, 2006, p.85), not enough challenging, diversifying and groundbreaking as culture and creativity are expected to be, but just a mere consumption rather than a real production process.

In many cases, the ECC approach was considered as too elitist determining the exclusion of the local residents in the events (Richards and Wilson, 2004). The main lessons have been the importance to promote the participation and the involvement of all the communities (such as the socially deprived ones) in the cultural and arts activity as has been the case for instance of the recent Liverpool ECC.

Some events are accused of lacking economic sustainability. The work only as a shortterm promotional device (Richards and Wilson, 2004, p.1947) could be a way for failing the important targets; furthermore, the economic development has to be taken into account but it should not be seen as a target disconnected from the other sectors.

Finally, the ECC can produce unbalanced urban effects. There are some references about the possibility of widening the gaps between city centre and periphery: the city centre is seen as a world class destination while the city's surrounding estates continue to be socially and economically deprived (Quinn, 2005).

As a final remark, it is important to point out that an EEC experience should be seen as part of an integrated urban policy and be conceived in a more holistic way (Quinn, 2005, p.927). It should be able to deal with the aims of the different sectors: taking into account the cultural, economic and spatial issues, skipping a higher focus on business necessities rather than those of culture or social approach. It should include the achievement of animating communities, celebrating diversity and improving quality of life of the local residents, and affecting positively the social and cultural justice issues (Richards and Wilson, 2004:1948).

\subsection{Enhancing approach}

This approach describes interventions wishing to promote the creative activity step-by-step, based on the continuous development and growth of the existing resources in the creative domain, such as the support to the local "creative class", including institutions and networks. The objective is mainly economic - to supply conditions for the growth of creative industries, to create and retain jobs. Though the means to achieve these goals are clearly distinct from other approaches (specially the Bulldozer-Business Approach), the centre here should be on a sustainable and gradual growth of the creative sector, involving as much as possible the creative actors community. 
The measures are focused on the support to an adequate environment ("creative milieu”), with the right conditions for the consolidation of the creative sector. In concrete, this approach can contemplate the requalification of public areas, the renovation of buildings for housing or to host cultural equipments and creative facilities (e.g., work/live buildings, fashion incubators) or educational facilities. In general, these interventions are carried out slowly in time, according to the needs and the dynamics of the place. Big urban developments, including the construction of new, large buildings, are left out of this approach. Results from several experiences denote that this local creative economy or creative quarters do promote economic growth and help to regenerate quarters. But, these processes, though not very demanding from the financial point of view, need time and persistence.

Sheffield is a paradigmatic example of this typology. The city started a quarter regeneration process in the early 1980s (the so-called Cultural Industries Quarter - CIQ) in a time where there was little know-how about policy-driven urban regeneration. The idea was to stimulate employment in the cultural sector, but also to enhance cultural provision and tourism. Some lack of coordination, a fragile public leadership and a too narrow vision resulted in serious weaknesses such as a lack of consumption places, animation and diversity. According to Moss (2002, p.218) the response to changing concepts of cultural quarters was so slow, and so late that the CIQ area could not handle the competitiveness of other places.

The main conclusion, was that "years of highly interventionist planning and the growth of local expertise in brokering substantial packages of international, national and local public money did not encourage slow, grass-roots development or a diversity of types of cultural enterprise” (Moss, 2002, p.218).

The evidence from this case and others shows that the key elements for the success of this approach are the participation of actors from the creative milieu in the development process. As they are the engines of the creative dynamics, they should be consulted regarding the preparation of the overall strategy and of the individual measures and their own initiatives should be supported.

The renovation measures should take into account the evolution of the housing prices and the guarantee of spaces at an affordable price. Low rents are a determinant factor in the attraction of an important segment of the creative class. Also the overall price in the area should be controlled, if possible, to allow the installation or the permanence of all day shops and services. An excessive increase of the housing costs leads to the abandon of the area by the creative segments with lower income and to the attraction of newcomers, resulting in gentrification phenomena and lately to a strong decrease in the creative activities. 
The main difficulty is to assure a minimum critical mass to promote a self-sustainable growth, by finding the right balance between endogenous resources (the creative residents) and new exogenous impulses, new creative actors, new activities, fresh ideas.

\subsection{The "Phoenix from the Ashes" approach}

This approach has been considered primarily on cities or quarters that were affected by a strong decline. Typically, these areas were dominated by certain industries, such as the steel and mining industry, in some cases important port or military areas and their surroundings may also gather the conditions for this approach. The concentration of heavy industries led to a high proportion of industrial workers in the population. In many cases, the industrial zone is in the centre of the city or district and it impregnates the daily-life and the mind-set of the population.

The industry shaped as well the cultural patterns, focused on leisure and entertainment for the working population, mainly as a compensation for the hard work. Higher educational and cultural institutions were rare and often deliberately not set up in the area. Accordingly, the cultural industry was on a very low level and its economic importance hardly existed.

The decay of these industries, due to several factors, has led to an economic and social decline and had also strong influence on the identity of the quarter or city and its people.

The "Phoenix from the Ashes" Approach tries to give such areas a new identity and new economic and social perspectives by the development of the cultural and creative industries. Old industrial zones and buildings function primarily as an "anchor" for identity and for a new (self) consciousness, in which culture plays a major role.

In particular, the objective is not to disregard the outdated industrial culture, but instead to "transform" it by adding new contents or values. Determinant is to deal with the industrial heritage and the industrial self-conscious of the area in a constructive way. This concerns mainly the former industrial areas and buildings, for which an original use is set up. As a result new facilities have been created in places where up to now only few cultural activities, equipments or institutions were located, or at least where certain fields of culture were barely established.

One important aspect is that the period for the definition and carrying out of the measures is not too long and that there are still buildings available, as physical symbols of this time. Buildings and areas have to be redesigned, but the post-industrial charm has to remain.

There are signs that a special ambiance, charm or "coolness" arises in the intervention areas making them more attractive for people, companies and institutions from outside. The newcomers are decisive as a trigger for economic development and change of image. At a later 
stage this economic dynamism expands to the rest of the economic branches and all the city or region profits from it.

An example for this approach is the Ruhr-area in Germany with the help of the programme of the "International Building Exhibition - IBA Emscherpark". In this programme three ways to deal with the old industrial heritage were applied in the context of "creative cities": 1) As an art object or art installation (for example the "Landschaftspark Duisburg Nord", (Beierlorzer, et al. $)^{11}$ ); 2) As a location for cultural facilities (concert halls, exhibition space, e.g. the "Jahrhunderthalle in Bochum") and as local cultural centres more on the level of city quarters (e.g. the "Zeche Karl”, in Essen; “Zentrum Altenberg”, in Oberhausen); 3) As integrated sites for educational institutions and companies in the creative / cultural sector (e.g. “Zeche Zollverein”, in Essen).

The main lessons to be learned are that dealing with the industrial heritage and the establishment of new institutions and clusters of cultural industries is a balancing act between the two extremes of "museum" and "island": If the focus lays too much on the preservation of old buildings and traditions, there is a risk that only a snapshot of the past is conserved and no new social and economic stimulus is generated (museum).

In the opposite extreme, new structures of creative industries are established in the centre of cities or districts, which work well internally, but have no relations to their surroundings. Then a synthetic/artificial seeming "creative island" arises from which the environment does not benefit much.

The main challenge is to generate a dynamics which guarantees that the attractiveness of the area is not just a "hype" that remains for a short period, but that on the long-term a cultural/creative milieu is consolidated, for the advantage of the city or region image, attracting people and institutions. For a sustainable and equitable development it is a condition that the local population is involved in the process and also benefits from it.

\footnotetext{
${ }^{11}$ http://www.landschaftspark.de/de/home/index.php.
} 


\section{CONCLUSIONS AND RECOMMENDATIONS}

From the seven categories of creative interventions, it is to highlight that each of them faces particular challenges and threats and should deal with these in a different way.

The Natural-born cities, such as London, Toronto or Berlin, due to their territorial dimension, their multidimensional challenges and the multitude of actors involved are confronted with the need to coordinate all these dimensions, all the actors and their own policies and measures. Governance is a key-issue and the lack of it may result in the waste of scarce resources or even in pervasive effects. These cities are also particularly exposed to international concurrence for the attraction of talents and of investments. They have to invest permanently in their attractiveness. This, of course, represents an important financial burden, and if they are not able to tackle it, they risk indebtment.

The approaches oriented to social inclusion are still rather neglected. Nevertheless, experience shows that they entail a strong potential, addressing the weaker aspects of the other approaches - integration of disadvantaged groups, unbalanced urban effects, increase of economic disparities, rejection by the population of the interventions and consequent need to reformulate plans. Their specific recommendations on the involvement of the residents, the creation of multidisciplinary teams for the setting up of new plans and policies, should be acknowledged by all the other approaches.

The Business approach impregnated by the clusters methodologies and principles seems to be particularly successful if the policy-makers consider the necessary minimum conditions to undertake a cluster policy.

The Bulldozer-business approach is strongly linked to the Business approach. Radical urban interventions are oriented to economic targets, either directly with the hosting of economic activities or indirectly by fostering a new attractive image. The challenges and the risks are however at a higher stake than those of the strict Business approach: their impacts are so significant that they may incur in repudiation by the public opinion and consequence movements by the population (e.g., demonstrations, public critics), in case their interests are not taken into consideration, endangering the image effect.

The European Capital of Culture approach ranges from immaterial measures, mainly event oriented (e.g., Luxembourg 2007), to the construction as well of flagship cultural buildings (e.g., Casa da Música, Oporto 2001²). These events are challenged by the need to spread their positive effects to the rest of the city, preventing unbalanced urban development, and above all, not just for the period of the exhibitions, but also in the future. The dynamics

\footnotetext{
${ }^{12}$ This equipment was, however, only concluded in 2005.
} 
generated have to prove to be sustainable, by the involvement of the local creative class in the initiatives and by the establishment of solid networks. Further, financial support is crucial at least for some time, to avoid a complete cooling down in the next years.

The Enhancing approach, particularly tempting for many medium-sized cities, due to the less demanding financial requests, is also not exempt of difficulties. A creative ambiance does not appear from dust, a bare minimum of creative animation is crucial and this "cheaper" option may turn up to be expensive in the long-term. Competition is tough, even in the same city, and there is a risk of a "jumping investment" policy, following the creative class from one creative quarter to the next.

Finally, the Phoenix Approach, as the Natural Born Approach, combines traces and risks from the Business, the Social, the Bulldozer and the Enhancing approaches, but with the disadvantage that these areas do not a tradition in creativity of bigger cities and possibly also not the financial resources. A good coordination is mandatory and especially the involvement of the local population is determinant for a sustainable development.

As a balance, evidence shows that there are two aspects which, despite all the different attributes, seem to be horizontal to all interventions: the involvement, motivation and respect for the local population and for the creative class, to prevent perverse effects and to reinforce the results of the initiatives, and supplementary measures ensuring sustainability, such as a good coordination and guaranteed financial resources for additional activities.

Policy-makers have as well to avoid serial reproductions, especially in the case of smaller cities, attracted by the vitality and the economic dynamics of bigger creative cities. It should be stressed, that in some cases the cities profited from rare opportunities, meaning that the used approach cannot be simply copied to another. For example, cases like Bilbao, where a big cultural institution like the Guggenheim foundation was investing, are seldom. Also not every city or region possess a usable old, empty derelict area that is big enough or an industrial remain which is impressive enough to be the base for approaches like the Phoenix.

The measures sustaining creative cities or quarter policies are always costly and before advancing with such a strategy it is decisive to investigate thoroughly the basic economic, social and cultural conditions, in particular the motivation of the creative industries stakeholders to become part of such a strategy.

Once the strategy is running, a sound system of monitoring and an on-going evaluation of the interventions are highly recommendable to be able to check at all stages the results of the policies and divergences towards the initial plans. One interesting option, first for a good preparation of a policy, latter on for a permanent update of the status of the policies, would be to make use of the so-called "trend scouts", meaning someone who is in touch with the actors and 
networks, and which reports about new trends, arising clusters, "hip" quarters, and so on, especially because this complex is rather dynamic.

As a final remark, for a sustainable creative development approach it is determinant to integrate the cultural policy in the urban/ regional spatial planning practices. 


\section{REFERENCES}

BEIERLORZER, Jasper, Taube (1997): Stadterneuerung im Ruhrgebiet, die IBA Emscherpark, in Monheim, Zöpel: Raum für Zukunft, Essen, p. 333.

BROOKES, C. et al. (2004): Culture and regeneration, an evaluation of the evidence, a study for Culture East Midlands, COMEDIA, Nottingham, p. 38.

CAREY, Charlotte (2006): Social inclusion and enterprise in the creative industries, PALATINE - Creative Enterprise in Higher Education, $<$ http://www.palatine.ac.uk/files/1402.pdf $>$.

COSTA, Pedro et al. (2008): On "creative cities" governance models: a comparative approach, The Service Industries Journal, 28:3, pp. 393-413.

Department for Culture Media and Sport (2001): Creative Industries Mapping Document, $<$ http://www.culture.gov.uk/images/publications/foreword.pdf $>$.

Department for Culture Media and Sport (2008): Creative Britain New Talents for the New Economy.

DIU (2002): Soziale Stadt, Info 10.

ERC Services Committee (2002): Creative industries development strategy, Executive summary,

<http://app.mti.gov.sg/data/pages/507/doc/ERC_SVS_CRE_Exec.pdf>.

EVANS, G. and P. Shaw (2004): The contribution of culture to regeneration in the UK: a review of evidence: A Report to the DCMS, LondonMet, p. 77.

FLORIDA, Charles (2002): The rise of the creative class, Basic Books, New York.

GARCÍA, Beatriz (2004): Urban regeneration, arts programming and major events, International Journal of Cultural Policy, 10:1, pp. 103-118. 
HALL, Peter (2007): World cities in the process of globalisation: challenges for Berlin, Presentation on the 13th of November 2007 to the Berlin Stadtforum, $<$ http://www.stadtentwicklung.berlin.de/planen/stadtforum/downloads/SF131107_Sir_Peter_Ha ll_Vortrag.pdf $>$.

HARTLEY, John (ed.) (2005): Creative industries, Blackwell, London, p. 414.

KEA (2006): Economy of culture in Europe, EC-DG Education and Culture.

KULTURDOKUMENTATION, Mediakult, Wifo (2004): Untersuchung des ökonomischen $\begin{array}{llll}\text { Potenzials } & \text { der } & \text { Industries", }\end{array}$ $<$ http://www.creativeindustries.at/pdf/Endbericht.pdf $>$.

$\begin{array}{lllllll}\text { LANDRY, Charles (n/d): London as a } & \text { Creative City, p. 12, }\end{array}$ $<$ http://www.cpu.gov.hk/english/documents/conference/e-landry.rtf>.

LANDRY, Charles (2000): The creative city: a toolkit for urban innovators, Comedia/Earthscan, London, p. 324.

LANGE, Bastian et al. (2008): Berlin's Creative Industries: Governing Creativity?, Industry and Innovation, Vol. 15.

LDA (2005): Strategies for creative spaces: Phase 1 Report, September 2005, p. 60, $<$ http://www.artistlink.org/files/Strategies\%20for\%20Creative\%20Spaces.pdf>.

LDA (2006a): Strategies for creative spaces: lessons learned, $<$ http://www.citiesinstitute.org/londonmet/library/a12324_3.pdf>.

LDA (2006b): Strategies for creative spaces - Berlin Case Study, $<$ http://www.citiesinstitute.org/londonmet/library/q70420_3.pdf>.

LDA (2006c): Strategies for creative spaces: Lessons learned, London development agency, $<$ http://www.citiesinstitute.org/londonmet/library/a12324_3.pdf>.

LOFTMAN, Patrick and Nevin, Brendan (1996): Going for Growth: Prestige Projects in Three British Cities, Urban Studies, Vol. 33:6, pp. 991-1019. 
MARTÍ, M. et al (n/d): El Proyecto 22@bcn: gobernanza local, renovación urbana e lucha vecinal en Barcelona, IGOP (Universitat Autònoma de Barcelona), Barcelona.

MCCARTHY, J., The Application of Policy for Cultural Clustering: Current Practice in Scotland, European Planning Studies, Vol. 14:3.

MILES, Malcolm (2005): Interruptions: Testing the Rhetoric of Culturally Led Urban Development, Urban Studies, Vol. 42:5/6, pp. 889-911.

NESTA (2006): Creating growth, how the UK can develop world class creative business, Report, NESTA.

O’CONNOR, J. (1999): The definition of 'cultural industries', Manchester Institute for Popular Culture, Manchester.

OLIVA, A. (2003): El districte dactivitats 22bcn, Aula Barcelona, Barcelona.

PADDISON, Ronan (1993): City Marketing, Image Reconstruction and Urban Regeneration, Urban Studies, Vol. 30:2, pp.339-350.

PRATT, Andy (2004): Mapping the Cultural Industries: Regionalisation; The Example of South East England, in Scott, (A. J.), Power, (D.), The Cultural Industries and the Production of Culture, London, Routledge.

QUINN, Bernadette (2005): Arts Festivals and the City, Urban Studies, Vol. 42:5/6, pp. 927943.

REASON, Matthew (2006): Glasgow's Year of Culture and Discourses of Cultural Policy on the Cusp of Globalisation, Contemporary Theatre Review, Vol. 16:1, pp.73-85.

RICHARDS, Greg and Wilson, Julie (2004): The impact of Cultural Events on city image: Rotterdam, Cultural Capital of Europe 2001.

RICHARDS, Greg et al. (2008): Luxembourg and Greater Region, European Capital of Culture 2007 - Final report, MCESR, Luxembourg. 
SÖNDERMANN, Michael (2006): Kulturwirtschaft, Das unentdeckte Kapital der Kommunen und Regionen, Nr.32, Konrad Adenauer Stiftung, Sankt Augustin.

TOWSE, Ruth (2003): Cultural industries, in Towse, Ruth, (ed.), A Handbook of Cultural Economics, Edward Elgar, Cheltenham, pp.170-182.

ZOLLVEREIN

Zentrum

der

Kreativwirtschaft,

$<$ http://www.zollverein.de/index.php?f_categoryId=761> . 